\title{
Long non-coding RNA in glioma: signaling pathways
}

\author{
Jia Shi ${ }^{1, *}$, Bo Dong ${ }^{1, *}$, Jiachao Cao ${ }^{1, *}$, Yumin Mao ${ }^{1}$, Wei Guan ${ }^{1}$, Ya Peng ${ }^{1}$ and Suinuan \\ Wang ${ }^{1}$ \\ ${ }^{1}$ Department of Neurosurgery, The Third Affiliated Hospital of Soochow University, Changzhou, China \\ * These authors have contributed equally to this work \\ Correspondence to: Suinuan Wang, email: wangsuinuan0019@126.com
}

Ya Peng, email: yapengczyy@126.com

Keywords: long non-coding RNAs, glioma, microRNA

Received: November 11,2016 Accepted: January 24, $2017 \quad$ Published: February 07, 2017

Copyright: Shi et al. This is an open-access article distributed under the terms of the Creative Commons Attribution License (CC-BY), which permits unrestricted use, distribution, and reproduction in any medium, provided the original author and source are credited.

\section{ABSTRACT}

Glioma is regarded as the most prevalent malignant carcinoma of the central nervous system. Thus, the development of new therapeutic strategies targeting glioma is of significant clinical importance. Long non-coding RNAs (IncRNAs) are functional RNA molecules without a protein-coding function and are reportedly involved in the initiation and progression of glioma. Dysregulation of IncRNAs in glioma is due to activation of several signaling pathways, such as the BRD4-HOTAIR- $\beta$-catenin/PDCD4, p53-Hif-H19/IGF2 and CRNDE/mTOR pathways. Furthermore, microRNAs (miRNAs) such as miR-675 also interact with IncRNAs in glioma. Thus, exploring the mechanisms by which IncRNA control processes will be instrumental for devising new effective therapies against glioma.

\section{INTRODUCTION}

Glioma is the most common and aggressive malignant tumor of the central nervous system and has a high rate of recurrence and mortality [1]. According to the histological subtype and degree of malignancy, gliomas can be classified as astrocytomas, oligodendrogliomas, ependymomas and mixed tumors, with grades of I to IV [2]. Although there have been advances in multimodal treatments such as surgery, radiotherapy and chemotherapy [3], overall survival of most patients with glioma remains dismal, especially in cases of glioblastoma, for which the median survival time is only approximately 14 months [4].

Tumor cell infiltration into normal brain tissue, which makes complete surgical excision challenging, is the main cause of the poor prognosis [5]. Compared to normal tissue, glioma cells exhibit an unbridled neoplastic growth pattern, which involves sustaining proliferative activity, enabling replicative immortality, opposing growth suppressors, resisting cell death, activating angiogenesis, promoting invasion and metastasis, reprogramming energy metabolism and evading immune destruction [6]. In addition, the heterogeneity of glioma cells makes them highly resistant to chemotherapy and radiotherapy $[7,8]$. Glioma cells not only exhibit the characteristics listed above but also exhibit obvious heterogeneity by recruiting undifferentiated and differentiated cells to form a "tumor microenvironment" for tumorigenesis [9] (Figure 1). Therefore, there is a strong need for a better understanding of the occurrence and evolution of glioma at the genetic and molecular levels, and such knowledge will be beneficial for identifying new therapeutic strategies.

IncRNA

Long non-coding RNAs (lncRNAs) are nonprotein-coding transcripts ranging from nearly 200 nucleotides $(\mathrm{nt})$ to over 100 kilobases $(\mathrm{kb})$ in length [1012]. According to their different genomic locations and context, IncRNAs can be classified into five categories: sense, transcribed from the sense strand of protein-coding genes; antisense, transcribed from the opposite strand of mRNAs; intronic, transcribed from introns of proteincoding genes; intergenic, transcribed from intergenic regions; and bidirectional, transcribed from the vicinity of transcription start sites in both sense and antisense directions [13]. As transcriptional regulators, lncRNAs can alter gene transcription via transcriptional interference and chromatin remodeling [14, 15]. Moreover, lncRNAs can also alter gene expression post-transcriptionally by base pairing with translation factors or ribosomes to control translation or by binding to splicing factors to modulate splicing $[16,17]$. Unlike microRNAs, which have been 
widely studied, little is known about the function of lncRNAs. However, evidence over the past 5 years has shown that lncRNAs have a significant function in tissue homeostasis and biological processes, including cancer progression [18].

Recently, several studies have indicated that aberrant expression of lncRNAs may affect glioma initiation and progression [19]; therefore, IncRNAs may act as biomarkers for glioma diagnosis, prognosis and target therapy [20]. In this review, we summarize the latest evidence for the roles of IncRNAs in regulating the biological behavior and the underlying mechanisms of glioma. Moreover, we provide an overview of the relationship between microRNA (miRNA) and lncRNA in glioma, which may lead to the identification of new therapeutic targets for this cancer.

\section{Differential IncRNA expression profiles in glioma}

Dysregulation of IncRNA in glioma and the degree of malignancy have been investigated in several genomewide profiling studies. Increased or decreased IncRNA expression results in a tumor suppressor or promoter role.
Table 1 summarizes the aberrant expression of lncRNAs in glioma reported to date.

\section{Dysregulation of IncRNA in glioma initiation}

Recent microarray studies have revealed significant changes in the expression patterns of many lncRNAs in tissues of different subtypes of glioma and normal brain tissue. Using the IncRNA classification pipeline, Zhang et al. identified 1970 lncRNAs across different types and grades of human gliomas [21]. Similarly, Grzmil et al. conducted profiling analysis of 30 different glioma samples (12 primary glioblastoma multiforme (GBM), 3 secondary GBM, 8 astrocytomas and 7 oligodendrogliomas) and 5 GBM cell lines. The results showed that 147 of 2448 IncRNAs were differentially expressed in tumor tissues compared to normal tissues and that 213 lncRNAs were differentially expressed in tumor cell lines [22]. Intestinally, both studies confirmed the up-regulation of HOX transcript antisense RNA (HOTAIR) and colorectal neoplasia differentially expressed (CRNDE) in tumor samples. Wang et al. reported that maternally expressed gene 3 (MEG3) expression was markedly decreased in

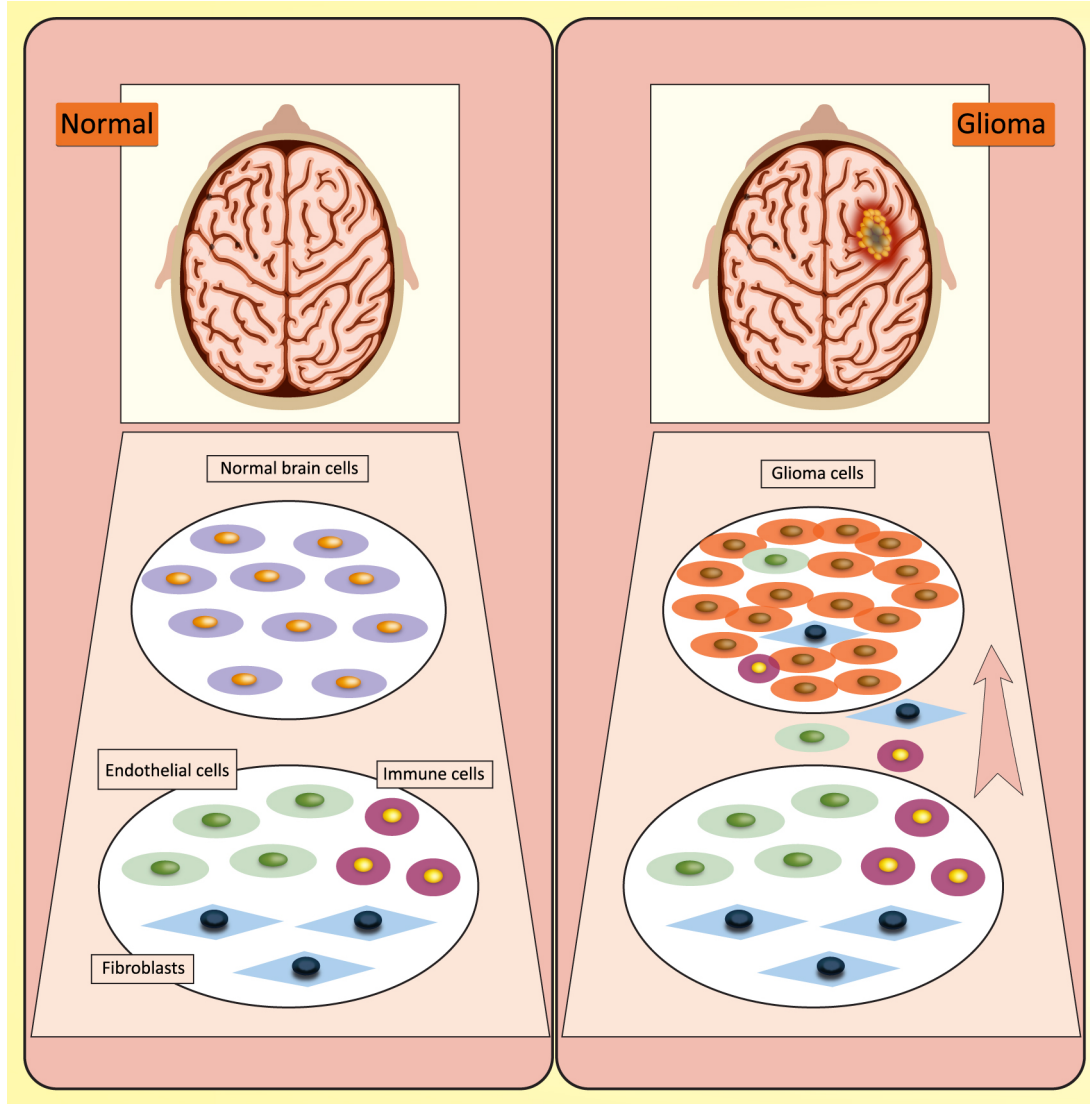

\section{GLIOMA CELL INFILTRATION}

- Sustaining proliferation

- Replicative immortality

- Evading growth suppressors

- Resisting cell death

- Activating angiogenesis

- Promoting invasion and metastasis

- Energy metabolism destruction

- Evading immune destruction

\section{TUMOR HETEROGENEITY}

- Endothelial cells

- Immune cells

- Fibroblast

- Bone-marrow derived cells

...

Figure 1: Characterization of glioma cells: infiltration and heterogeneity. Infiltration: glioma cells exhibit a special growth pattern, involving sustaining proliferative activity, enabling replicative immortality, opposing growth suppressors, resisting cell death, activating angiogenesis, promoting invasion and metastasis, reprogramming energy metabolism and evading immune destruction. Heterogeneity: glioma cells recruit undifferentiated and differentiated cells to form a "tumor microenvironment" for tumorigenesis. 
Table 1: Dysregulation of IncRNAs in glioma initiation and progression.

\begin{tabular}{|l|c|c|c|}
\hline \multicolumn{1}{|c|}{ IncRNA } & Changes & Target & Ref. \\
\hline HOTAIR1 & up & $\beta$-catenin/PDCD4 & {$[21,22,33-36]$} \\
\hline CCAT2 & up & $\beta$-catenin & $[40], 22,52]$ \\
\hline CRNDE & up & mTOR & {$[24]$} \\
\hline ASLNC22381 & up & IGF1 & {$[24]$} \\
\hline ASLNC20819 & up & IGF1 & {$[26,28,44-49]$} \\
\hline H19 & up & & {$[26]$} \\
\hline ENST00000545440 & up & & {$[55]$} \\
\hline NR_002809 & up & & {$[25]$} \\
\hline MALAT1 & down & ERK-MAPK/MMP2/9 & {$[25]$} \\
\hline TUG1 & down & Caspase3/9 & {$[25]$} \\
\hline PART1 & down & & {$[23]$} \\
\hline MIAT & down & & {$[21]$} \\
\hline GAS5 & down & & {$[26]$} \\
\hline MEG3 & down & & {$[27,28]$} \\
\hline C21 orf131 & down & & {$[27,28]$} \\
\hline BC002811 & down & & \\
\hline XLOC_010967 & down & & \\
\hline PAR5 & down & & \\
\hline RFPL1S & down & & \\
\hline
\end{tabular}

HOTAIR: HOX transcript antisense RNA; CCAT2: cancer-associated transcript 2; CRNDE: colorectal neoplasia differentially expressed; MALAT1: metastasis-associated lung adenocarcinoma transcript 1; TUG1: taurine up-regulated gene 1; PART1: prostate androgen-regulated transcript 1; MIAT: myocardial infarction associated transcript ; GAS5: growth arrest specific 5; MEG3: maternally expressed gene 3; PAR5: Prader Willi/Angelman region RNA 5; RFPL1S: RFPL1 antisense 1; $\beta$-catenin: catenin beta-1; PDCD4: programmed cell death protein 4; mTOR: mammalian Target of RapamycinIGF1: insulin growth factor 1; IGF2: insulin growth factor 2; ERK: extracellular signal-regulated kinases; MAPK: mitogen-activated protein kinase; MMP2/9: matrix metalloproteinase-2/9; Caspase3/9: cysteine-aspartic proteases.

astrocytoma tissues compared to adjacent normal tissues. Moreover, MEG3 was positively associated with p53, and this association was necessary for activation of p53 [23].

GBM is the most common and aggressive type of primary brain tumor in humans. In a study by Han et al., 1308 lncRNAs were identified (654 up-regulated and 654 down-regulated) between GBM tissues and normal brain tissues (fold change $\geq 4.0$ or $\leq 0.25, \mathrm{P}<0.01$ ). Further gene network analysis suggested that ASLNC22381 and ASLNC20819 are up-regulated by targeting insulin growth factor 1 (IGF1) in GBM recurrence and progression [24]. Zhang et al. also identified reduced expression of prostate androgen-regulated transcript 1 (PART1), myocardial infarction-associated transcript (MIAT) and growth arrest specific 5 (GAS5) in GBM tumors [25]. These findings suggest that dysregulation of lncRNA expression may be an early event during tumorigenesis, and these lncRNAs may have potentially important functions in glioma initiation.

\section{Dysregulation of IncRNA in the malignant progression of glioma}

By comparing different lncRNA profiles between low-grade and high-grade astrocytoma, Zhang et al [21] identified 45 lncRNAs. Among these lncRNAs, 12 were found to be closely related to malignant progression. For example, expression of HOTAIR1 and CRNDE was enhanced with ascending tumor grade, though that of MEG3 and C21orf131 (LINC00320) was reduced [21]. In another study, Zhi et al. identified 7 differentially expressed lncRNAs between astrocytoma samples (World Health Organization WHO II-IV) and normal adjacent tissues using a commercial microarray platform. Unsupervised clustering analysis further demonstrated that up-regulation of ENST00000545440 and NR 002809 was positively associated with advanced clinical stages of astrocytoma. Moreover, Kaplan-Meier survival analysis showed that down-regulation of BC002811 and XLOC_010967 or up-regulation of NR_002809 was significantly associated with poor survival [26].

Other studies provide comparable evidence. For instance, Vital et al. investigated 46 lncRNAs differently expressed between 5 low-grade astrocytomas and 30 high-grade astrocytomas [27], and Zhou et al. described 48 lncRNAs differently expressed in 13 astrocytic gliomas (6 low grade and 7 high grade) [28]. Among these dysregulated lncRNAs, H19 expression increased with the tumor malignancy grade, whereas expression of Prader Willi/Angelman region RNA 5 (PAR5) and RFPL1 antisense 1 (RFPL1S) decreased with increasing 
tumor grade [27, 28]. These differential levels of lncRNA expression between malignancy grades indicate their involvement in glioma progression.

\section{MECHANISMS OF LNCRNA IN GLIOMA (TABLE 1)}

\section{The pro-oncogenic IncRNA network}

\section{BRD4-HOTAIR- $\beta$-catenin/PDCD4}

Bromodomain and extraterminal (BET) domain proteins are epigenetic modulators that have recently emerged as promising therapeutic targets in GBM [29-31]. Bromodomain containing 4 (BRD4), a BET protein, has been well-studied in glioma and has been demonstrated to bind to the HOTAIR promoter [32]. The lncRNA HOTAIR is identified as an oncogene in GBM; by interacting with polycomb repressive complex 2 (PRC2), HOTAIR is positively associated with glioma staging, poor prognosis and the molecular subtype of glioma [33]. Treatment with a BET inhibitor (I-BET151) decreases expression of HOTAIR and suppresses tumor cell proliferation by inducing cell cycle arrest. Conversely, overexpression of HOTAIR abrogates the anti-proliferative activity of I-BET151, a major target for GBM therapy [32]. Moreover, glioma stem cells (GSCs), a subpopulation of glioma cells, have important functions in sensitivity to chemoradiotherapy and the possibility of tumor recurrence [34]. Kan Fang et al. and Xuan Zhou et al. reported reducing HOTAIR expression inhibited GSC proliferation, induced cell cycle arrest, decreased cell invasive capacity and reduced tumorigenic capacity both in vivo and in vitro $[35,36]$. The underlying mechanism was mediated via activation of programmed cell death protein 4 (PDCD4) expression at the transcriptional level [36] and repression of the $\beta$-catenin pathway [35]. The Wnt/ $\beta$ catenin pathway was also shown to be associated with malignant progression and the poor prognosis of glioma patients [37-39]. Another IncRNA, cancer-associated transcript 2 (CCAT2), was found to be up-regulated in glioma tissues and positively correlated with tumor stage. Indeed, knockdown of CCAT2 inhibited glioma cell proliferation and migration by repressing the $\mathrm{Wnt} / \beta$ catenin pathway [40]. Therefore, the findings with regard to BRD4-HOTAIR- $\beta$-catenin/PDCD4-mediated tumor development provide new insight into the complexity of glioma.

\section{P53-HIF1-H19/IGF2}

H19 is a 2.3-kb non-coding RNA that is widely expressed during embryonic development, which then decreases after birth [41]. Mounting evidence has demonstrated that expression of $\mathrm{H} 19$ is enhanced in both primary and metastatic tumors, including during morphogenesis and the epithelial-mesenchymal transition (EMT), and in inflammatory and multidrug-resistant tumors $[42,43]$. The role of H19 in glioma has also recently been highlighted. Jiang $\mathrm{X}$ et al. reported that overexpression of $\mathrm{H} 19$ promotes the invasion, stemness, angiogenesis and tumorigenicity of glioblastoma cells, indicating the function of $\mathrm{H} 19$ in the tumorigenicity and stemness of glioma [44]. IGF2 is transcribed from four different promoters (P1-P4) and produces 4 different transcripts that share common regulatory sequences with $\mathrm{H} 19$, which is located within $200 \mathrm{~kb}$ downstream of the parental IGF2 gene at 11p.15.5 [45]. Several studies have shown that both IGF2-P4 transcripts and H19 are highly expressed in human glioblastoma cell lines and high-grade gliomas, affecting cell growth and motility $[45,46]$. Moreover, hypoxia is a common feature of solid tumors, particularly malignant gliomas, and causes tumor cells to either die or exhibit a pleiotropic adaptive response by activating hypoxia-inducible transcription factor 1 (HIF1) [47]. Park et al. demonstrated that H19 expression was enhanced in p53 knockout mice upon hypoxia [48]; however, in the presence of functional p53, H19 was efficiently repressed via inhibition of HIF 1- $\alpha$ transcriptional activity [49], demonstrating an important role of the p53-HIF1-H19 pathway in hypoxia. Additionally, IFG2 is also a target gene transactivated by HIF1 during the hypoxic response [47]. These studies highlight the p53-HIF-H19/IGF2 axis as a potential therapeutic target for glioma.

\section{CRNDE/mTOR}

lncRNA CRNDE, on chromosome 16 of the human genome, is the most up-regulated transcript in colorectal cancer [50]. Interestingly, a study by Zhang et al. showed that among 129 differentially expressed lncRNAs, CRNDE is also the most up-regulated lncRNA in glioma [21]. Moreover, correlation analysis demonstrated that the level of CRNDE is positively associated with tumor grade [22]. Mammalian Target of Rapamycin (mTOR) is a well-known regulator of cell growth and proliferation, and dysregulation of mTOR by either oncogene activation or tumor suppressor loss can induce tumor growth in various malignant cell lines [51]. Wang et al. reported that overexpression of CRNDE promotes cell growth and migration both in vivo and in vitro by increasing the phosphorylation level of p70S6K, a direct downstream target of mTOR. In contrast, CRNDE knockdown suppressed these processes by decreasing p70S6K phosphorylation, suggesting that CRNDE can influence mTOR signaling in glioma [52].

\section{The tumor-suppressive IncRNA network}

\section{MALAT1/MMP2/ERK/MAPK}

The lncRNA metastasis-associated lung adenocarcinoma transcript 1 (MALAT1) is initially 
A

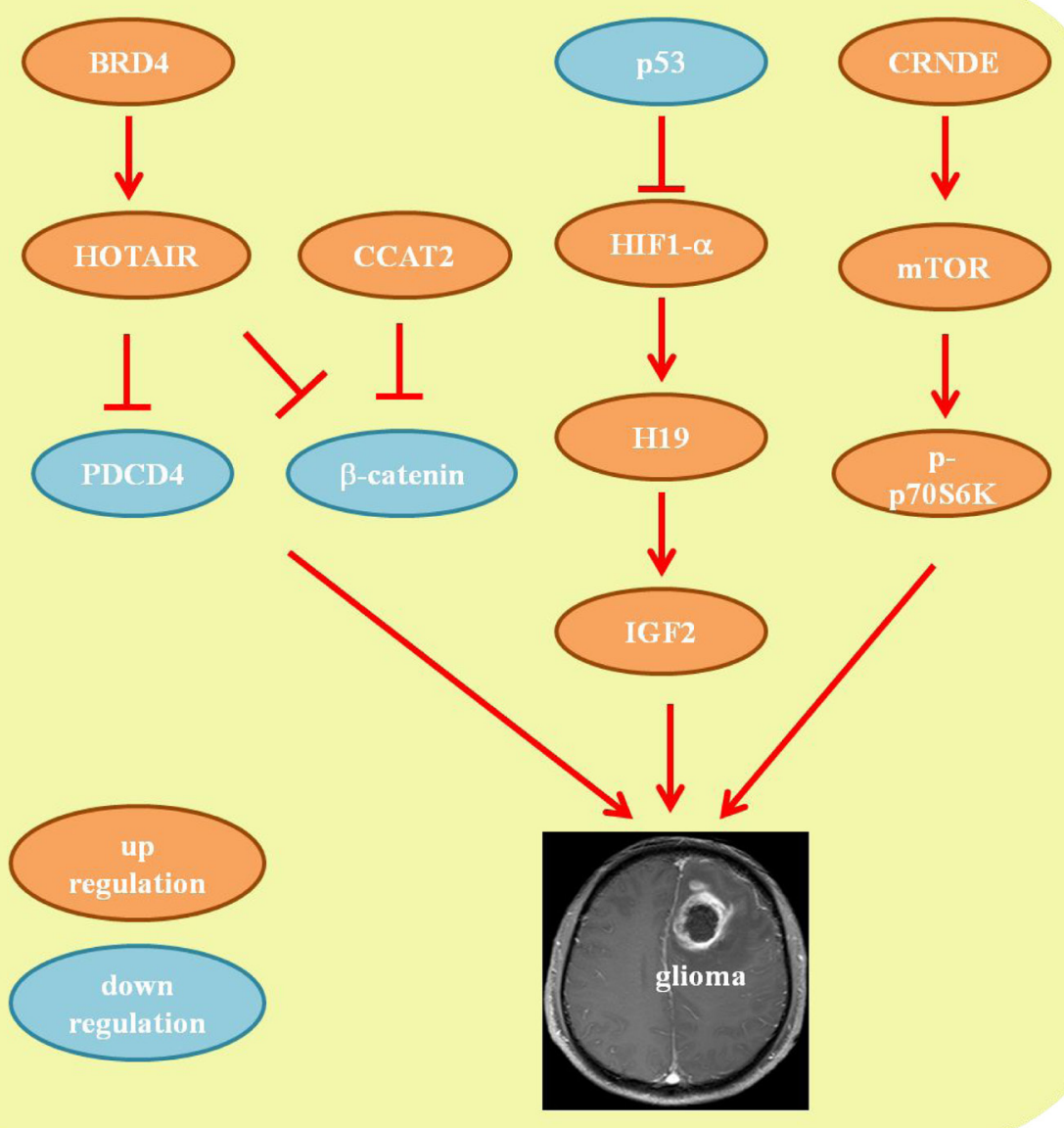

B
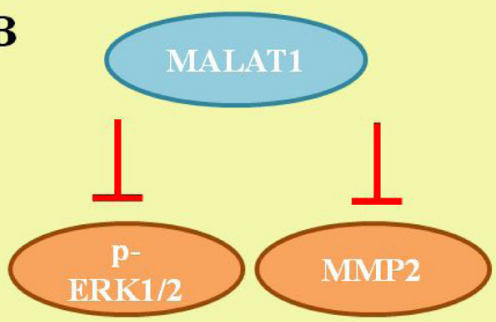

up

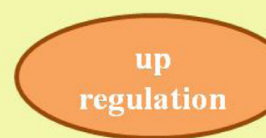

down

regulation
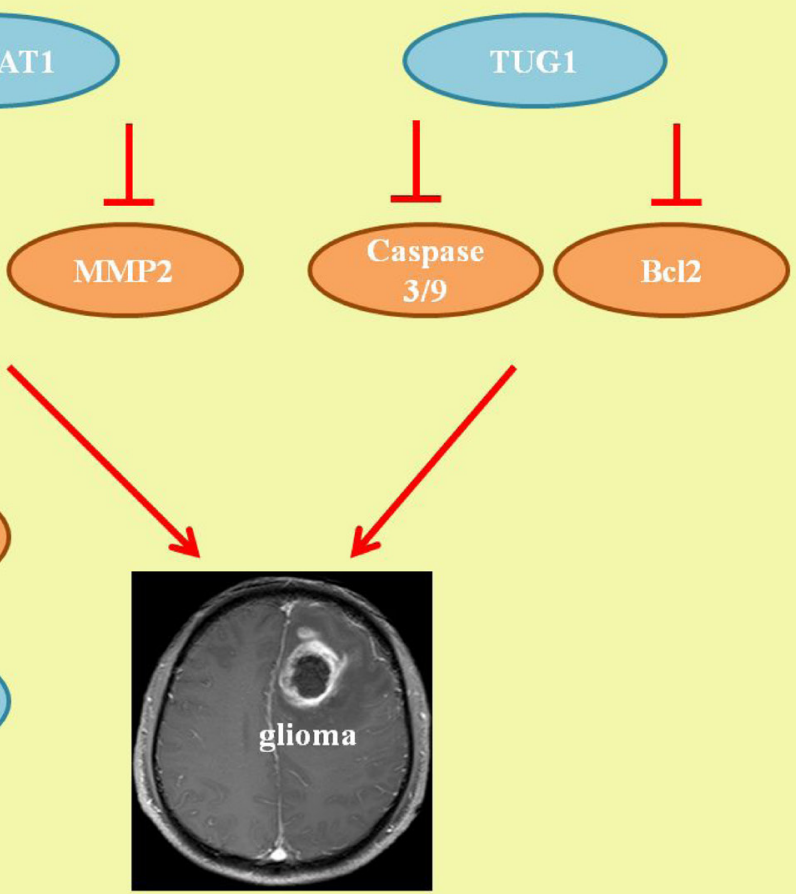

Figure 2: Mechanisms of IncRNA in glioma. A. The pro-oncogenic IncRNA network. B. The tumor-suppressive lncRNA network. 
Table 2: MiRNA-IncRNA interactions in glioma.

\begin{tabular}{|l|c|c|c|c|}
\hline \multicolumn{1}{|c|}{ IncRNA } & Changes & miRNA & Changes & Ref. \\
\hline HOTAIR & up & miR-148b & down & {$[72]$} \\
\hline & & miR-326 & down & {$[73]$} \\
\hline H19 & up & miR-675 & up & {$[76,77]$} \\
\hline & & miR-29a & up & {$[78]$} \\
\hline CRNDE & up & miR-186 & down & {$[81]$} \\
\hline XIST & up & miR-152 & down & {$[83,84]$} \\
\hline CASC2 & down & miR-21 & up & {$[89]$} \\
\hline
\end{tabular}

HOTAIR: HOX transcript antisense RNA; CRNDE: colorectal neoplasia differentially expressed; XIST: X-inactive specific transcript; CASC2: cancer susceptibility candidate 2.

up-regulated in lung cancer, which is reported to be a favorable prognostic factor for patients with stage I non-small cell lung cancer $[53,54]$. Recently, Han et al. reported reduced expression of MALAT1 in glioma tissues relative to that in normal brain tissues, with MALAT1 knockdown promoting cell proliferation and invasion both in human glioma cell lines and in glioma xenograft models. Conversely, overexpression of MALAT1 counteracted the significant repression of cell proliferation and invasion in vitro and in vivo, indicating a tumor-suppressive role for MALAT1 in glioma [55]. It is well known that tumor invasion and spread are the major causes of death in patients with glioma. The extracellular signal-regulated kinase/mitogen activated protein kinase (ERK/MAPK) pathway is one of the most important signal transduction pathways responsible for cell proliferation and invasion [56]. Matrix metalloproteinase 2 and 9 (MMP2 and -9) are also known to participate in cell invasion during enhanced tumor progression [57]. Mechanistic studies have demonstrated that overexpression of MALAT1 significantly decreases expression of phosphorylated ERK1/2 and MMP2/9 in U87 and U251 cells. Moreover, inhibition of ERK signaling (U0126) imitates MALAT1 overexpression-induced levels of phosphorylated ERK1/2 and MMP2, indicating that the tumor-suppressive function of MALAT1 is mediated by attenuating ERK/MAPKmediated cell growth and MMP2/9-mediated invasiveness [55].

\section{TUG1/caspase-3/caspase-9/Bcl2}

Taurine up-regulated gene 1 (TUG1) is a $7.1-\mathrm{kb}$ lncRNA that was initially detected in a genomic screen of retinal cells under taurine treatment [58]. The role of TUG1 in glioma pathogenesis was recently identified by several studies $[59,60]$. Li et al. showed that expression of TUG1 was significantly inhibited in glioma, with negative correlations with tumor size, World Health Organization (WHO) grade and overall survival. Overexpression of TUG1 induces apoptosis in glioma cells by activating apoptotic genes caspase-3 and -9-mediated intrinsic pathways and inhibiting anti-apoptotic gene $\mathrm{Bcl} 2$ mediated anti-apoptotic pathways, suggesting a tumor suppressor role for TUG1 in human glioma [59].

\section{MIRNA-LNCRNA INTERACTION IN GLIOMA}

miRNAs are 20-25 nt non-coding RNA molecules that act as repressors of gene expression by binding to partially complementary sequences in mRNA 3' untranslated regions (UTRs) [61]. Distinct expression patterns and the functional significance of miRNAs have been reported for many cancers, including glioma [62]. miRNAs appear to be important regulators of GSC maintenance [63-65], invasiveness [64, 65], pathogenesis $[66,67]$ and epigenetic and signaling pathways $[68,69]$. Recently, emerging evidence has linked miRNAs with lncRNAs in controlling glioma initiation and progression and has suggested that the miRNA-lncRNA interaction may provide novel insight into therapeutic targets for glioma (Table 2).

Expression of miR-148b-3p, a member of the miR$148 / 152$ family, is decreased in several tumor cell lines $[70,71]$. Guan Wang et al. reported that miR-148b-3p suppresses glioma cell proliferation, cell cycle progression and invasion by inhibiting HOTAIR expression. Furthermore, it was demonstrated that miR-148b-3p binds to HOTAIR in a sequence-specific manner [72]. Additionally, HOTAIR can affect the malignant biological behavior of glioma by targeting miRNA. miR-326, which is down-regulated in both glioma samples and in two glioma cell lines (U87 and U251), showed a negative correlation with histopathological grades of glioma [73, 74]. Jing Ke et al. determined that HOTAIR promotes the development of glioma by inhibiting miR-326 and further promoting increased expression of fibroblast growth factor 1 (FGF1) [73], which has a significant oncogenic function in tumorigenesis through activation of the MEK $1 / 2$ and PT3K/AKT pathways [75].

MicroRNA-675 (miR-675-5p), a miRNA in the first exon of H19, is up-regulated in several cancer types, including glioma [76]. Yan Shi et al. and Chao Li et al. reported overexpression of H19 to be positively correlated with its derivate miR-675 in promoting glioma cell invasion and proliferation, though reduction of H19 inhibited miR-675 expression, thus abrogating carcinogenesis. Bioinformatics and luciferase reporter 
assays have further confirmed the underlying mechanisms; miR-675 inhibits cadherin $13\left(\mathrm{Ca}^{2+}\right.$-dependent cell adhesion) or cyclin-dependent kinase 6 (CDK6) by directly targeting the binding site within the 3'UTR $[76,77]$. Interestingly, as we demonstrated previously, hypoxia is considered a major driving force for glioma growth and angiogenesis. Alessia LD et al. showed that overexpression of miR-675-5p is sufficient to induce hypoxia under normoxia by increasing nuclear HIF-1 $\alpha$ and its mRNA; moreover, depletion of miR-675-5p drastically abolishes hypoxia by decreasing levels of HIF-1 $\alpha$ [77]. The H19-miR-675-HIF-1 $\alpha$ loop network may provide a novel strategy for the hypoxia response in glioma. In addition to miR-675, miR-29a is also a potential target for H19 in glioma angiogenesis. Indeed, knockdown of H19 inhibits glioma and induces endothelial cell proliferation, migration and tube formation by decreasing expression of miR-29a. Additionally, miR-29a targets the 3'UTR region of vasohibin 2 (VASH2), which was identified as an angiogenic factor in tumor tissue [78].

miR-186 has been reported to be a tumor suppressor, and its expression is decreased in many tumors, such as esophageal cancer, lung adenocarcinoma and colorectal cancer [79, 80]. Recently, Zhang et al. showed that overexpression of CRNDE could promote GSC proliferation and invasion and inhibit apoptosis by suppressing miR-186. Mechanistic studies further revealed that miR-186 decreases expression of X-linked inhibitor of apoptosis (XIAP) and serine/threonine-protein kinase 7 (PAK7) by binding to their 3'UTR regions [81].

By inhibiting Kruppel-like factor 4 (Klf4), miR152 is reported to be a tumor suppressor in human GSCs [82]. In a study by Yao et al., miR-152 was identified as a direct target of lncRNA X-inactive specific transcript (XIST), a product of the XIST gene, which regulates $\mathrm{X}$ inactivation in mammals $[83,84]$. Knockdown of XIST exerted a tumor-suppressive function by decreasing GSC proliferation, migration and invasion as well as by promoting apoptosis. In vivo studies also showed that knockdown of XIST repressed tumor growth and induced high survival rates in nude mice. Knockdown of XIST also increased expression of miR-152, whereas overexpression of miR-152 reduced XIST expression and reversed the effects of XIST knockdown [84]. These results suggest that XIST and miR-152 may form a reciprocal repression feedback loop in glioma.

miR-21 is a well-known oncogene that is elevated in various malignant tumors, including glioma tissues and cell lines [85]. A growing body of literature has shown that knockdown of miR-21 inhibits tumorigenesis by regulating multiple factors associated with cell proliferation, migration, invasion and apoptosis [86, 87]. The lncRNA cancer susceptibility candidate 2 (CASC2), located on chromosome 10q26, acts as a tumor-suppressor in endometrial cancer [88]. Recently, Wang et al. found CASC2 to be down-regulated in glioma tissues and cell lines, though overexpression of CASC2 repressed glioma cell proliferation, malignancy and invasion and promoted apoptosis by directly inhibiting miR-21. Moreover, mechanistic analysis confirmed that miR-21 binds to CASC2 in a sequence-specific manner. In addition, introduction of miR-21 significantly repressed CASC2mediated inhibition of glioma cell proliferation, migration, invasion and apoptosis, suggesting reciprocal repression between CASC2 and miR-21 [89].

\section{CONCLUSIONS}

Recent studies of IncRNA and glioma have generated much interest in the field of cancer. Reports have demonstrated that lncRNAs exert significant biological functions in gliomas, including the initiation of malignancy, progression and other phenotypes. Here, we discussed dysregulation of lncRNA expression in glioma and the underlying mechanisms, which may potentially lead to the discovery of novel diagnostic and prognostic biomarkers.

However, some aspects need to be further explored. First, given that tumor cells exhibit obvious heterogeneity by recruiting various cells to form the tumor microenvironment [90], little is known about the relationship between IncRNAs and tumor heterogeneity. Second, although lncRNAs have been reported to participate in the progression of glioma, the stage at which lncRNAs function remains unknown. To address these issues, additional studies in large cohorts are needed to elucidate the specific and underlying regulatory pathways of lncRNAs in gliomas. Further knowledge of these lncRNAs may provide novel therapeutic strategies for glioma.

\section{CONFLICTS OF INTEREST}

The authors declare that there are no conflicts of interest.

\section{FUNDS}

No funding was received for this review.

\section{REFERENCES}

1. Lai NS, Wu DG, Fang XG, Lin YC, Chen SS, Li ZB, $\mathrm{Xu}$ SS. Serum microRNA-210 as a potential noninvasive biomarker for the diagnosis and prognosis of glioma. Br J Cancer. 2015; 112: 1241-1246.

2. Louis DN, Ohgaki H, Wiestler OD, Cavenee WK, Burger PC, Jouvet A, Scheithauer BW, Kleihues P. The 2007 WHO classification of tumours of the central nervous system. Acta Neuropathol. 2007; 114: 97-109.

3. Mansouri A, Mansouri S, Hachem LD, Klironomos G, 
Vogelbaum MA, Bernstein M, Zadeh G. The role of 5 -aminolevulinic acid in enhancing surgery for high-grade glioma, its current boundaries, and future perspectives: a systematic review. Cancer. 2016; 122: 2469-2478.

4. Delgado-López PD, Corrales-García EM. Survival in glioblastoma: a review on the treatment modalities. Clin Transl Oncol. 2016; 18: 1062-1071.

5. Verburg N, Pouwels PJ, Boellaard R, Barkhof F, Hoekstra OS, Reijneveld JC, Vandertop WP, Wesseling P, de Witt Hamer PC. Accurate delineation of glioma infiltration by advanced PET/MR neuro-imaging (FRONTIER Study): a diagnostic study protocol. Neurosurgery. 2016; 79: 535540 .

6. Hanahan D, Weinberg RA. Hallmarks of cancer: the next generation. Cell. 2011; 144: 646-674.

7. Hadjipanayis CG, Van Meir EG. Tumor initiating cells in malignant gliomas: biology and implications for therapy. $\mathrm{J}$ Mol Med (Berl). 2009; 87: 363-374.

8. Gourlay J, Morokoff AP, Luwor RB, Zhu HJ, Kaye AH, Stylli SS. The emergent role of exosomes in glioma. J Clin Neurosci. 2017; 35: 13-23.

9. Rolle K. miRNA Multiplayers in glioma. From bench to bedside. Acta Biochim Pol. 2015; 62: 353-365.

10. Gibb EA, Brown CJ, Lam WL. The functional role of long non-coding RNA in human carcinomas. Mol Cancer. 2011; 10: 38 .

11. Mills JD, Chen J, Kim WS, Waters PD, Prabowo AS, Aronica E, Halliday GM, Janitz M. Long intervening noncoding RNA 00320 is human brain-specific and highly expressed in the cortical white matter. Neurogenetics. 2015; 16: 201-213.

12. Hsiao J, Yuan TY, Tsai MS, Lu CY, Lin YC, Lee ML, Lin SW, Chang FC, Liu Pimentel H, Olive C, Coito C, Shen G, Young M, et al. Upregulation of haploinsufficient gene expression in the brain by targeting a long non-coding RNA improves seizure phenotype in a model of Dravet syndrome. EBioMedicine. 2016; 9: 257-277.

13. Ma L, Bajic VB, Zhang Z. On the classification of long noncoding RNAs. RNA Biol. 2013; 10: 925-933.

14. Martianov I, Ramadass A, Serra Barros A, Chow N, Akoulitchev A. Repression of the human dihydrofolate reductase gene by a non-coding interfering transcript. Nature. 2007; 445: 666-670.

15. Rinn JL, Kertesz M, Wang JK, Squazzo SL, Xu X, Brugmann SA, Goodnough LH, Helms JA, Farnham PJ, Segal E, Chang HY. Functional demarcation of active and silent chromatin domains in human HOX loci by noncoding RNAs. Cell. 2007; 129: 1311-1323.

16. Tsuiji H, Yoshimoto R, Hasegawa Y, Furuno M, Yoshida $\mathrm{M}$, Nakagawa $\mathrm{S}$. Competition between a noncoding exon and introns: Gomafu contains tandem UACUAAC repeats and associates with splicing factor-1. Genes Cells. 2011; 16: 479-490.

17. Tripathi V, Ellis JD, Shen Z, Song DY, Pan Q, Watt AT,
Freier SM, Bennett CF, Sharma A, Bubulya PA, Blencowe BJ, Prasanth SG, Prasanth KV. The nuclear-retained noncoding RNA MALAT1 regulates alternative splicing by modulating SR splicing factor phosphorylation. Mol Cell. 2010; 39: 925-938.

18. Tano K, Akimitsu N. Long non-coding RNAs in cancer progression. Front Genet. 2012; 3: 219.

19. Bian EB, Li J, Xie YS, Zong G, Li J, Zhao B. LncRNAs: new players in gliomas, with special emphasis on the interaction of lncRNAs With EZH2. J Cell Physiol. 2015; 230: 496-503.

20. Sun L, Hui AM, Su Q, Vortmeyer A, Kotliarov Y, Pastorino S, Passaniti A, Menon J, Walling J, Bailey R, Rosenblum M, Mikkelsen T, Fine HA. Neuronal and glioma-derived stem cell factor induces angiogenesis within the brain. Cancer Cell. 2006; 9: 287-300.

21. Zhang X, Sun S, Pu JK, Tsang AC, Lee D, Man VO, Lui WM, Wong ST, Leung GK. Long non-coding RNA expression profiles predict clinical phenotypes in glioma. Neurobiol Dis. 2012; 48: 1-8.

22. Grzmil M, Morin P Jr, Lino MM, Merlo A, Frank S, Wang Y, Moncayo G, Hemmings BA. MAP kinase-interacting kinase 1 regulates SMAD2-dependent TGF-beta signaling pathway in human glioblastoma. Cancer Res. 2011; 71: 2392-2402.

23. Wang P, Ren Z, Sun P. Overexpression of the long non-coding RNA MEG3 impairs in vitro glioma cell proliferation. J Cell Biochem. 2012; 113: 1868-1874.

24. Han L, Zhang K, Shi Z, Zhang J, Zhu J, Zhu S, Zhang A, Jia Z, Wang G, Yu S, Pu P, Dong L, Kang C. LncRNA pro fi le of glioblastoma reveals the potential role of lncRNAs in contributing to glioblastoma pathogenesis. Int J Oncol. 2012; 40: 2004-2012.

25. Zhang XQ, Sun S, Lam KF, Kiang KM, Pu JK, Ho AS, Lui WM, Fung CF, Wong TS, Leung GK. A long noncoding RNA signature in glioblastoma multiforme predicts survival. Neurobiol Dis. 2013; 58: 123-131.

26. Zhi F, Wang Q, Xue L, Shao N, Wang R, Deng D, Wang S, Xia X, Yang Y. The use of three long non-coding RNAs as potential prognostic indicators of astrocytoma. PLoS One. 2015; 10: e0135242.

27. Vital AL, Tabernero MD, Castrillo A, Rebelo O, Tao H, Gomes F, Nieto AB, Resende Oliveira C, Lopes MC, Orfao A. Gene expression profiles of human glioblastomas are associated with both tumor cytogenetics and histopathology. Neuro Oncol. 2010; 12: 991-1003.

28. Zhou J, Xu T, Yan Y, Qin R, Wang H, Zhang X, Huang Y, Wang Y, Lu Y, Fu D, Chen J. MicroRNA-326 functions as a tumor suppressor in glioma by targeting the Nin one binding protein (NOB1). PLoS One. 2013; 8: e68469.

29. Filippakopoulos P, Knapp S. Targeting bromodomains: epigenetic readers of lysine acetylation. Nat Rev Drug Discov. 2014; 13: 337-356.

30. Papavassiliou KA, Papavassiliou AG. Bromodomains: 
pockets with therapeutic potential. Trends Mol Med. 2014; 20: 477-478.

31. Pastori C, Daniel M, Penas C, Volmar CH, Johnstone AL, Brothers SP, Graham RM, Allen B, Sarkaria JN, Komotar RJ, Wahlestedt C, Ayad NG. BET bromodomain proteins are required for glioblastoma cell proliferation. Epigenetics. 2014; 9: 611-620.

32. Pastori C, Kapranov P, Penas C, Peschansky V, Volmar CH, Sarkaria JN, Bregy A, Komotar R, St Laurent G, Ayad NG, Wahlestedt C. The Bromodomain protein BRD4 controls HOTAIR, a long noncoding RNA essential for glioblastoma proliferation. Proc Natl Acad Sci U S A. 2015; 112: 83268331.

33. Zhang K, Sun X, Zhou X, Han L, Chen L, Shi Z, Zhang A, Ye M, Wang Q, Liu C, Wei J, Ren Y, Yang $\mathrm{J}$, et al. Long non-coding RNA HOTAIR promotes glioblastoma cell cycle progression in an EZH2 dependent manner. Oncotarget. 2015; 6: 537-546. doi: 10.18632/ oncotarget.2681.

34. Codrici E, Enciu AM, Popescu ID, Mihai S, Tanase C. Glioma stem cells and their microenvironments: providers of challenging therapeutic targets. Stem Cells Int. 2016; 2016: 5728438 .

35. Zhou X, Ren Y, Zhang J, Zhang C, Zhang K, Han L, Kong L, Wei J, Chen L, Yang J, Wang Q, Zhang J, Yang Y, et al. HOTAIR is a therapeutic target in glioblastoma. Oncotarget. 2015; 6: 8353-8365. doi: 10.18632/oncotarget.3229.

36. Fang K, Liu P, Dong S, Guo Y, Cui X, Zhu X, Li X, Jiang L, Liu T, Wu Y. Magnetofection based on superparamagnetic iron oxide nanoparticle-mediated low lncRNA HOTAIR expression decreases the proliferation and invasion of glioma stem cells. Int J Oncol. 2016; 49: 509-518.

37. Shi Z, Qian X, Li L, Zhang J, Zhu S, Zhu J, Chen L, Zhang K, Han L, Yu S, Pu P, Jiang T, Kang C. Nuclear translocation of beta-catenin is essential for glioma cell survival. J Neuroimmune Pharmacol. 2012; 7: 892-903.

38. Kaur N, Chettiar S, Rathod S, Rath P, Muzumdar D, Shaikh ML, Shiras A. Wnt3a mediated activation of Wnt/ beta-catenin signaling promotes tumor progression in glioblastoma. Mol Cell Neurosci. 2013; 54: 44-57.

39. Kim KH, Seol HJ, Kim EH, Rheey J, Jin HJ, Lee Y, Joo $\mathrm{KM}$, Lee J, Nam DH. Wnt/beta-catenin signaling is a key downstream mediator of MET signaling in glioblastoma stem cells. Neuro Oncol. 2013; 15: 161-171.

40. Guo H, Hu G, Yang Q, Zhang P, Kuang W, Zhu X, Wu L. Knockdown of long non-coding RNA CCAT2 suppressed proliferation and migration of glioma cells. Oncotarget. 2016; 7: 81806-81814. doi: 10.18632/oncotarget.13242.

41. Li W, Jiang P, Sun X, Xu S, Ma X, Zhan R. Suppressing H19 modulates tumorigenicity and stemness in U251 and U87MG glioma cells. Cell Mol Neurobiol. 2016: 1-9.

42. Fellig Y, Ariel I, Ohana P, Schachter P, Sinelnikov I, Birman T, Ayesh S, Schneider T, de Groot N, Czerniak A, Hochberg A. H19 expression in hepatic metastases from a range of human carcinomas. J Clin Pathol. 2005; 58: 10641068.

43. Tsang WP, Kwok TT. Riboregulator H19 induction of MDR1-associated drug resistance in human hepatocellular carcinoma cells. Oncogene. 2007; 26: 4877-4881.

44. Jiang X, Yan Y, Hu M, Chen X, Wang Y, Dai Y, Wu D, Wang Y, Zhuang Z, Xia H. Increased level of H19 long noncoding RNA promotes invasion, angiogenesis, and stemness of glioblastoma cells. J Neurosurg. 2016; 124: 129-136.

45. Amit D, Hochberg A. Development of targeted therapy for a broad spectrum of cancers (pancreatic cancer, ovarian cancer, glioblastoma and HCC) mediated by a double promoter plasmid expressing diphtheria toxin under the control of H19 and IGF2-P4 regulatory sequences. Int J Clin Exp Med. 2012; 5: 296-305.

46. Amit D, Matouk IJ, Lavon I, Birman T, Galula J, AbuLail R, Schneider T, Siegal T, Hochberg A, Fellig Y. Transcriptional targeting of glioblastoma by diphtheria toxin-A driven by both $\mathrm{H} 19$ and IGF2-P4 promoters. Int J Clin Exp Med. 2012; 5: 124-135.

47. Gariboldi MB, Ravizza R, Monti E. The IGFR1 inhibitor NVP-AEW541 disrupts a pro-survival and pro-angiogenic IGF-STAT3-HIF1 pathway in human glioblastoma cells. Biochem Pharmacol. 2010; 80: 455-462.

48. Park IY, Sohn BH, Choo JH, Joe CO, Seong JK, Lee YI, Chung JH. Deregulation of DNA methyltransferases and loss of parental methylation at the insulin-like growth factor II (Igf2)/H19 loci in p53 knockout mice prior to tumor development. J Cell Biochem. 2005; 94: 585-596.

49. Matouk IJ, Mezan S, Mizrahi A, Ohana P, Abu-Lail R, Fellig Y, Degroot N, Galun E, Hochberg A. The oncofetal H19 RNA connection: hypoxia, p53 and cancer. Biochim Biophys Acta. 2010; 1803: 443-451.

50. Kumar A, Suthers PF, Maranas CD. MetRxn: a knowledgebase of metabolites and reactions spanning metabolic models and databases. BMC Bioinformatics. 2012; $13: 6$.

51. Zhou H, Huang S. mTOR signaling in cancer cell motility and tumor metastasis. Crit Rev Eukaryot Gene Expr. 2010; 20: 1-16.

52. Wang Y, Wang Y, Li J, Zhang Y, Yin H, Han B. CRNDE, a long-noncoding RNA, promotes glioma cell growth and invasion through mTOR signaling. Cancer Lett. 2015; 367: 122-128.

53. Gutschner T, Hammerle M, Diederichs S. MALAT1 - a paradigm for long noncoding RNA function in cancer. $\mathrm{J}$ Mol Med (Berl). 2013; 91: 791-801.

54. Ji P, Diederichs S, Wang W, Boing S, Metzger R, Schneider PM, Tidow N, Brandt B, Buerger H, Bulk E, Thomas M, Berdel WE, Serve H, et al. MALAT-1, a novel noncoding RNA, and thymosin beta4 predict metastasis and survival in early-stage non-small cell lung cancer. Oncogene. 2003; 22: 8031-8041. 
55. Han $Y$, Wu Z, Wu T, Huang Y, Cheng Z, Li X, Sun T, Xie X, Zhou Y, Du Z. Tumor-suppressive function of long noncoding RNA MALAT1 in glioma cells by downregulation of MMP2 and inactivation of ERK/MAPK signaling. Cell Death Dis. 2016; 7: e2123.

56. Kohsaka S, Hinohara K, Wang L, Nishimura T, Urushido M, Yachi K, Tsuda M, Tanino M, Kimura T, Nishihara H, Gotoh N, Tanaka S. Epiregulin enhances tumorigenicity by activating the ERK/MAPK pathway in glioblastoma. Neuro Oncol. 2014; 16: 960-970.

57. Forsyth PA, Wong H, Laing TD, Rewcastle NB, Morris DG, Muzik H, Leco KJ, Johnston RN, Brasher PM, Sutherland G, Edwards DR. Gelatinase-A (MMP-2), gelatinase-B (MMP-9) and membrane type matrix metalloproteinase-1 (MT1-MMP) are involved in different aspects of the pathophysiology of malignant gliomas. Br J Cancer. 1999; 79: 1828-1835.

58. Young TL, Matsuda T, Cepko CL. The noncoding RNA taurine upregulated gene 1 is required for differentiation of the murine retina. Curr Biol. 2005; 15: 501-512.

59. Li J, Zhang M, An G, Ma Q. LncRNA TUG1 acts as a tumor suppressor in human glioma by promoting cell apoptosis. Exp Biol Med (Maywood). 2016; 241: 644-649.

60. Cai H, Xue Y, Wang P, Wang Z, Li Z, Hu Y, Li Z, Shang $X$, Liu Y. The long noncoding RNA TUG1 regulates blood-tumor barrier permeability by targeting miR144. Oncotarget. 2015; 6: 19759-19779. doi: 10.18632/ oncotarget. 4331 .

61. Godnic I, Zorc M, Jevsinek Skok D, Calin GA, Horvat S, Dove P, Kovac M, Kunej T. Genome-wide and specieswide in silico screening for intragenic MicroRNAs in human, mouse and chicken. PLoS One. 2013; 8: e65165.

62. Godlewski J, Krichevsky AM, Johnson MD, Chiocca EA, Bronisz A. Belonging to a networkmicroRNAs, extracellular vesicles, and the glioblastoma microenvironment. Neuro Oncol. 2015; 17: 652-662.

63. Katsushima K, Kondo Y. Non-coding RNAs as epigenetic regulator of glioma stem-like cell differentiation. Front Genet. 2014; 5: 14.

64. Chu PM, Ma HI, Chen LH, Chen MT, Huang PI, Lin SZ, Chiou SH. Deregulated microRNAs identified in isolated glioblastoma stem cells: an overview. Cell Transplant. 2013; 22: 741-753.

65. Godlewski J, Newton HB, Chiocca EA, Lawler SE. MicroRNAs and glioblastoma; the stem cell connection. Cell Death Differ. 2010; 17: 221-228.

66. Godlewski J, Bronisz A, Nowicki MO, Chiocca EA, Lawler S. microRNA-451: a conditional switch controlling glioma cell proliferation and migration. Cell Cycle. 2010; 9: 27422748.

67. Godlewski J, Nowicki MO, Bronisz A, Nuovo G, Palatini J, De Lay M, Van Brocklyn J, Ostrowski MC, Chiocca EA, Lawler SE. MicroRNA-451 regulates LKB1/AMPK signaling and allows adaptation to metabolic stress in glioma cells. Mol Cell. 2010; 37: 620-632.

68. Kreth S, Thon N, Kreth FW. Epigenetics in human gliomas. Cancer Lett. 2014; 342: 185-192.

69. Bronisz A, Wang Y, Nowicki MO, Peruzzi P, Ansari KI, Ogawa D, Balaj L, De Rienzo G, Mineo M, Nakano I, Ostrowski MC, Hochberg F, Weissleder R, et al. Extracellular vesicles modulate the glioblastoma microenvironment via a tumor suppression signaling network directed by miR-1. Cancer Res. 2014; 74: 738-750.

70. Song YX, Yue ZY, Wang ZN, Xu YY, Luo Y, Xu HM, Zhang X, Jiang L, Xing CZ, Zhang Y. MicroRNA-148b is frequently down-regulated in gastric cancer and acts as a tumor suppressor by inhibiting cell proliferation. Mol Cancer. 2011; 10: 1.

71. Song $\mathrm{Y}, \mathrm{Xu} \mathrm{Y}$, Wang Z, Chen Y, Yue Z, Gao P, Xing C, $\mathrm{Xu} \mathrm{H}$. MicroRNA-148b suppresses cell growth by targeting cholecystokinin-2 receptor in colorectal cancer. Int J Cancer. 2012; 131: 1042-1051.

72. Wang G, Li Z, Tian N, Han L, Fu Y, Guo Z, Tian Y. miR$148 \mathrm{~b}-3 \mathrm{p}$ inhibits malignant biological behaviors of human glioma cells induced by high HOTAIR expression. Oncol Lett. 2016; 12: 879-886.

73. Ke J, Yao YL, Zheng J, Wang P, Liu YH, Ma J, Li Z, Liu XB, Li ZQ, Wang ZH, Xue YX. Knockdown of long non-coding RNA HOTAIR inhibits malignant biological behaviors of human glioma cells via modulation of miR326. Oncotarget. 2015; 6: 21934-21949. doi: 10.18632/ oncotarget. 4290.

74. Qiu S, Lin S, Hu D, Feng Y, Tan Y, Peng Y. Interactions of miR-323/miR-326/miR-329 and miR-130a/miR-155/ miR-210 as prognostic indicators for clinical outcome of glioblastoma patients. J Transl Med. 2013; 11: 10.

75. Hadari YR, Gotoh N, Kouhara H, Lax I, Schlessinger J. Critical role for the docking-protein FRS2 alpha in FGF receptor-mediated signal transduction pathways. Proc Natl Acad Sci U S A. 2001; 98: 8578-8583.

76. Shi Y, Wang Y, Luan W, Wang P, Tao T, Zhang J, Qian J, Liu N, You Y. Long non-coding RNA H19 promotes glioma cell invasion by deriving miR-675. PLoS One. 2014; 9: e86295.

77. Li C, Lei B, Huang S, Zheng M, Liu Z, Li Z, Deng Y. H19 derived microRNA-675 regulates cell proliferation and migration through CDK6 in glioma. Am J Transl Res. 2015; 7: 1747-1764.

78. Jia P, Cai H, Liu X, Chen J, Ma J, Wang P, Liu Y, Zheng J, Xue Y. Long non-coding RNA H19 regulates glioma angiogenesis and the biological behavior of gliomaassociated endothelial cells by inhibiting microRNA-29a. Cancer Lett. 2016; 381: 359-369.

79. Cai J, Wu J, Zhang H, Fang L, Huang Y, Yang Y, Zhu X, Li R, Li M. miR-186 downregulation correlates with poor survival in lung adenocarcinoma, where it interferes with cell-cycle regulation. Cancer Res. 2013; 73: 756-766.

80. Zhao BS, Liu SG, Wang TY, Ji YH, Qi B, Tao YP, Li 
$\mathrm{HC}, \mathrm{Wu} \mathrm{XN}$. Screening of microRNA in patients with esophageal cancer at same tumor node metastasis stage with different prognoses. Asian Pac J Cancer Prev. 2013; 14: 139-143.

81. Zheng J, Li XD, Wang P, Liu XB, Xue YX, Hu Y, Li Z, Li ZQ, Wang ZH, Liu YH. CRNDE affects the malignant biological characteristics of human glioma stem cells by negatively regulating miR-186. Oncotarget. 2015; 6: 2533925355. doi: 10.18632/oncotarget.4509.

82. Ma J, Yao Y, Wang P, Liu Y, Zhao L, Li Z, Li Z, Xue Y. MiR-152 functions as a tumor suppressor in glioblastoma stem cells by targeting Kruppel-like factor 4. Cancer Lett. 2014; 355: 85-95.

83. Brown CJ, Ballabio A, Rupert JL, Lafreniere RG, Grompe M, Tonlorenzi R, Willard HF. A gene from the region of the human $\mathrm{X}$ inactivation centre is expressed exclusively from the inactive $X$ chromosome. Nature. 1991; 349: 38-44.

84. Yao Y, Ma J, Xue Y, Wang P, Li Z, Liu J, Chen L, Xi Z, Teng H, Wang Z, Li Z, Liu Y. Knockdown of long noncoding RNA XIST exerts tumor-suppressive functions in human glioblastoma stem cells by up-regulating miR-152. Cancer Lett. 2015; 359: 75-86.

85. Asangani IA, Rasheed SA, Nikolova DA, Leupold JH, Colburn NH, Post S, Allgayer H. MicroRNA-21 (miR21) post-transcriptionally downregulates tumor suppressor Pdcd4 and stimulates invasion, intravasation and metastasis in colorectal cancer. Oncogene. 2008; 27: 2128-2136.
86. Zhou X, Zhang J, Jia Q, Ren Y, Wang Y, Shi L, Liu N, Wang G, Pu P, You Y, Kang C. Reduction of miR-21 induces glioma cell apoptosis via activating caspase 9 and 3. Oncol Rep. 2010; 24: 195-201.

87. Gabriely G, Wurdinger T, Kesari S, Esau CC, Burchard J, Linsley PS, Krichevsky AM. MicroRNA 21 promotes glioma invasion by targeting matrix metalloproteinase regulators. Mol Cell Biol. 2008; 28: 5369-5380.

88. Baldinu P, Cossu A, Manca A, Satta MP, Sini MC, Rozzo C, Dessole S, Cherchi P, Gianfrancesco F, Pintus A, Carboni A, Deiana A, Tanda F, et al. Identification of a novel candidate gene, $\mathrm{CASC} 2$, in a region of common allelic loss at chromosome 10q26 in human endometrial cancer. Hum Mutat. 2004; 23: 318-326.

89. Wang P, Liu YH, Yao YL, Li Z, Li ZQ, Ma J, Xue YX. Long non-coding RNA CASC2 suppresses malignancy in human gliomas by miR-21. Cell Signal. 2015; 27: 275-282.

90. Welker AM, Jaros BD, Puduvalli VK, Imitola J, Kaur B, Beattie CE. Correction: Standardized orthotopic xenografts in zebrafish reveal glioma cell-line-specific characteristics and tumor cell heterogeneity. Dis Model Mech. 2016; 9: 1063-1065. 